\title{
Experts and elephants: local ecological knowledge predicts landscape use for a species involved in human-wildlife conflict
}

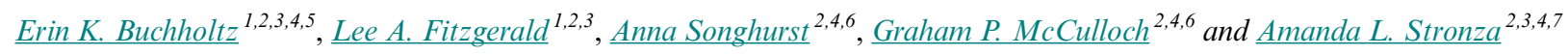

\begin{abstract}
Local ecological knowledge (LEK) has been increasingly invoked in biodiversity monitoring and conservation efforts. Although methods involving LEK have become more widespread in ecology, it remains an undervalued source of information in understanding the ecology of wildlife in the context of human-wildlife conflict. People who regularly interact with wildlife, and often with notable consequences, as is the case with human-wildlife conflict, will likely build up ecological knowledge of that species. We gathered LEK on the landscape use of the African elephant (Loxodonta Africana) in a region where its range overlaps with human land use and results in conflict, the western Okavango Panhandle of Botswana. We interviewed community-defined local experts and used participatory ranking activities to gather information on landscape use of elephants. The scores from the rankings were then incorporated with environmental data following resource selection function methods common in ecology. The resulting LEK-based model had high predictive ability for elephant locations when modeled at a local scale $(25 \mathrm{~km}$, Spearman's rho $=0.98, P<0.0001)$. We also calculated resource selection models using elephant telemetry data combined with the same environmental data as the LEK models. These models showed a complementary pattern, with better predictive ability at the regional scale $($ Spearman's rho $=0.98, P<0.0001)$ than at the local scale (rho $=0.92, P<0.0031$ ). In addition to being used for the resource selection functions, each method provided different kinds of information on elephant landscape use. Our results support the use of LEK as a tool for understanding local patterns of wildlife landscape use in the context of human-wildlife conflict, where the knowledge can be used to complement other data across scales and the use of which can itself contribute to better conservation outcomes.
\end{abstract}

Key Words: African elephant; Botswana; human-elephant conflict; LEK; resource selection function

\section{INTRODUCTION}

Multidisciplinary approaches to science that rely on different types of data and knowledge have the potential to result in new and more comprehensive ways of understanding and addressing conservation challenges. Local ecological knowledge (LEK) is the "knowledge held by a specific group of people about their local ecosystems" (Olsson and Folke 2001) and broadly encompasses the experiential knowledge that is attained through resource use and interactions with a local environment. Recognizing the rich field of study on the topic within the social sciences, LEK has been included increasingly in ecological research as a valuable source of knowledge in social-environmental systems (Brook and McLachlan 2008). Moreover, government and nongovernmental organizations often rely on reports and articles from scientific experts, who may or may not be local, to make management decisions. Including local experts' knowledge in ecological research is just one small step toward recognizing the value of LEK and including it in the process of conservation and management decision-making.

LEK can provide valuable contributions to answering ecological questions. LEK is complex and can encompass ways of knowing that are unique and separate from typical ecological research methodology. While different worldviews are a valuable source of knowledge and contribute to understanding the relationships between people and the environment, there are also elements of LEK that can be readily incorporated into ecological studies in the lens of "western" science. For example, LEK has been used to model distributions of rare ungulates for landscape conservation prioritization in the Caribbean (Turvey et al. 2015), to determine tortoise abundances in Spain (Anadón et al. 2010), and to estimate changes in species abundance for Atlantic fisheries (Bender et al. 2014). Additionally, studies have found that LEKbased data are concordant with those collected using conventional ecological methods such as telemetry or camera traps (Meijaard et al. 2011, Turvey et al. 2014, Parry and Peres 2015). Studies such as these often rely on the experiential knowledge of people who encounter wildlife species to understand more about how wildlife use their environment.

Within ecological modeling, understanding how wildlife use their environment is often accomplished using resource selection function methods. Resource selection functions rank or compare the areas that wildlife use with those that are not used, and these models are often based on telemetry data gathered from GPS or radio-transmitting devices on individual animals (Boyce et al. 2002). However, knowledge of areas used or not used by wildlife is not only available through telemetry; in fact, many resource selection functions are parameterized based on what ecologists refer to as "expert opinion" (Zeller et al. 2012). Expert opinion usually refers to the knowledge held by or the modeling decisions made by people such as researchers or land managers. Through the lens of LEK, individuals who have extensive experiential knowledge about a particular species can therefore provide integral information that fits within the resource selection function framework as experts. This framework with local experts

${ }^{1}$ Ecology \& Evolutionary Biology Program, Texas A\&M University, ${ }^{2}$ Applied Biodiversity Science Program, Texas A\&M University, ${ }^{3}$ Department of Ecology and Conservation Biology, Texas A\&M University, ${ }^{4}$ The Ecoexist Project, Maun, Botswana, ${ }^{5}$ Current affiliation: U.S. Geological Survey, Fort Collins, CO, USA, ${ }^{6}$ Department of Zoology, University of Oxford, ${ }^{7}$ Department of Rangeland, Wildlife, and Fisheries Management, Texas A\&M University 
and expert opinion has been used previously for caribou resource selection functions in Canada using a specific type of LEK, traditional ecological knowledge, and telemetry data (Polfus et al. 2014).

Both telemetry- and LEK-based approaches have many ways to contribute to the understanding of how wildlife use their environment and can be complementary in the types and relevant scales of information gathered. Telemetry can provide data on the trajectories of individual animals during a set period of time; one possible use of those data is for a resource selection function model to find statistical patterns, allowing researchers to extrapolate patterns based on those individuals across the tracked range. In contrast, a group of people may be exposed to many animals within a familiar region, and some of those people will accumulate knowledge about those animals across a variety of environments and interactions over time. In this case, knowledge can form the basis for a resource selection function that predicts local patterns of resource use based on the wildlife population's local behaviors. These two approaches may then provide complementary models of how wildlife use the environment, with different insights depending on the research questions, objectives, and scales.

The question of wildlife resource use is particularly important because people and wildlife increasingly interact and compete for space and resources. Overlapping human development and wildlife ranges can lead to negative interactions, or humanwildlife conflict (HWC). HWC represents a critical conservation challenge (Madden 2004, Nyhus 2016) that affects both wildlife populations and human well-being. The effects of conflict can range from opportunity costs and property damage to livestock or crop loss and animal or human fatalities. To understand better the drivers of HWC, telemetry has been widely used to track animals and understand species that overlap with humans in rural and urban areas. However, many animals alter their behavior in proximity to human activity and development (Gaynor et al. 2018), making it crucial to look at local landscape use when trying to pinpoint conflict-related behavior. Because telemetry-based studies of animal movement are based on the frequency with which individuals move through different locations of interest, whether the resulting models are accurate at the local scales relevant for HWC is dependent on the behavior of the specific collared individuals. This situation sets the stage for different approaches to complement each other by characterizing wildlife movement at both broad and local scales of interest. These findings, in turn, can inform both conservation efforts and mitigation strategies for reducing negative interactions between people and wildlife.

With its basis in local experiential knowledge, LEK can provide information on how wildlife responds to features close to human settlements and within the space that people move through in their daily lives. LEK can include information on animal preferences for specific habitat features or plant species within the knowledge-holder's area of experience, and that information may be more detailed than the data collected from satellite images. Therefore, these different types of knowledge may provide insights at two complementary spatial scales: the range-wide scale from telemetry and the human location-centric scale from LEK.
People who experience frequent interactions with wildlife are particularly well-suited to build knowledge and insight about those species. People who experience HWC are often surveyed to quantify conflict incidents and effects (e.g., Gusset et al. 2009, Karanth et al. 2012), their specific attitudes and perceptions related to human-wildlife conflict (e.g., Oli et al. 1994, NaughtonTreves et al. 2003, Kansky and Knight 2014, Kansky et al. 2014), and their mitigation behaviors (e.g., Treves et al. 2006, Graham and Ochieng 2008, Tshering and Thinley 2017). However, LEK has so far been underused as a source of natural history and animal behavior knowledge about species involved in conflict. Accounting for people's attitudes toward wildlife is important for conflict research (Dickman 2010, Kansky et al. 2014, 2016). However, in doing so, it is possible to see people only as victims of conflict and overlook them as experts on the natural history of their local ecosystem. The frequent, and often negative, exposure to wildlife species associated with conflict can lead people to pay close attention to the movement and behavior of that species, building up detailed knowledge. This knowledge is attained at a specific local scale of the area where people are active. This, in turn, is also a very relevant scale at which to answer ecological questions about wildlife in proximity to humans and human development.

We aimed to test how LEK about the landscape use of a species involved in conflict could complement telemetry-based data in a resource-selection framework, and at what scales these types of knowledge are most informative. We focused on the African savanna elephant (Loxodonta africana), which is capable of carrying GPS collars for satellite tracking and telemetry data. It is ecologically important to understand elephant behavior and movement at various spatial scales, including broad movements across its range. Savanna elephants are also well-suited for people to have experiential knowledge of them; the species is highly detectable and has noteworthy impacts on people's lives and livelihoods. The presence of elephants can be considered dangerous, resulting in everything from minor property damage to entire crops lost to foraging, and most devastatingly, injury or death to people. People go to great lengths to protect themselves and their crops from elephants; they may alter their activities throughout the day to avoid areas with elephants and stay awake all night to try and scare elephants away from their fields. Therefore, in addition to understanding the broad ecological relationship between elephants and the environment, it is also important to understand elephant ecology at the local scale around villages because that is where conflict between people and elephants occurs. This information can then be used to mitigate and manage conflicts; for example, predicting areas of frequent use by elephants that overlap with people's resource use around villages (Buchholtz et al. 2019b) can help inform land-use planning and development of wildlife corridors to reduce negative interactions.

Our objectives were to identify elephant use of vegetation, habitat types, and landscape features in the western Okavango Panhandle of Botswana using LEK. We collected data from communitydefined local experts and used those data to parameterize resource selection models at two spatial scales. We expected that if the LEK-based models had high predictive power for elephant presence on the landscape, we would find a correlation between 
the ranking of the habitat selection class and the number of elephant locations within that class based on existing GPS collar data. We also modeled a telemetry-based resource selection model to test how the predictive power of LEK- and telemetry-based methods differed at multiple scales of analysis.

\section{METHODS}

\section{Study area}

The western Okavango Panhandle (hereafter, Panhandle) is located in northern Botswana and is characterized by the Okavango River and associated wetland, which provide a permanent source of water for the people and wildlife that live there (Fig. 1). The region is bordered to the north and west by Namibia. Hereafter, we use "regional" to refer to analyses and conclusions about the project study area of the western Okavango Panhandle.

Fig. 1. Map of the study region (dashed black line) in the western Okavango Panhandle in northwestern Botswana. The five focal villages (black circles) are indicated with their names, and the locations of villages with $>200$ people in the 2011 census are also indicated (gray circles).

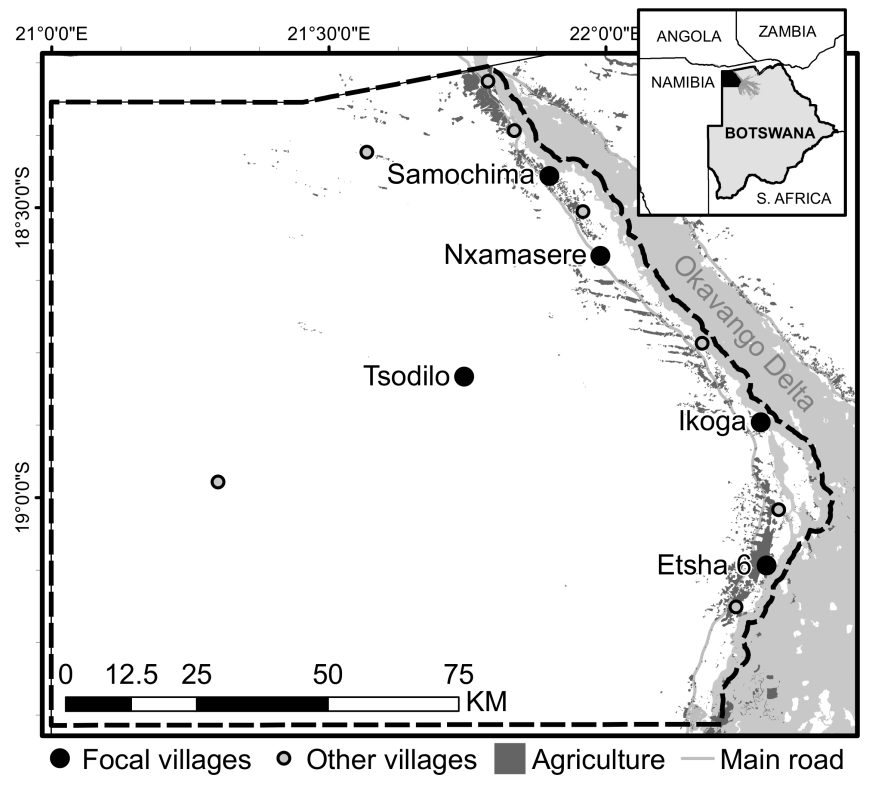

We conducted LEK surveys in five villages within the project area. From north to south, the villages of Samochima, Nxamasere, Ikoga, and Etsha 6 occur along the river. Tsodilo lies centrally in the region and near the culturally important and recognized UNESCO World Heritage Site of Tsodilo Hills. BaHambukushu and BaYei are the dominant tribes in these villages and in the region. Subsistence farming and cattle herding are the main livelihoods. There is a history of relocation; BaHambukushu civil war refugees immigrated from Namibia and Angola in the late 1960s and were resettled in the southern Panhandle, including the focal villages of Ikoga and Etsha 6 (Potten 1976). We focused on the LEK held by individuals of these tribes, rather than indigenous or traditional ecological knowledge, to capture those individuals' knowledge of elephants in the area where they currently live.
The elephant population in the Panhandle moves throughout the region, which has no formal wildlife protected areas and limited semipermeable barriers such as fences. The elephant population was estimated to be 2242 in 2012 (Botswana Department of Wildlife and National Parks 2013), although with a low sampling intensity (only 1.56\%). Elephants are associated with HWC in the area, including crop-raiding, property damage, and human injury or death. An average of 390 unique elephant-related HWC incidents were reported to the Botswana Department of Wildlife and National Parks in the project area each year between 2010 and the time of the survey in 2017.

\section{Environmental variables}

We considered three broad classes of environmental variables: vegetation species, habitat types, and landscape features (Table A1 in Appendix 1). We developed a list of 15 vegetation species based on existing literature (Peace Parks Foundation 2005, Vanderpost et al. 2014) and our experience in the field, with four additional species added at the suggestion of LEK participants. Eleven categorical habitat classes were included, based on our knowledge, work by Vanderpost et al. (2014), and an existing classification of the Kavango-Zambezi land classes (Peace Parks Foundation 2005, 250-m resolution). We hand-digitized agricultural areas based on 2017 Google Earth imagery. Eleven landscape features were considered based on our knowledge of the landscape. Topographic landscape features and topographic position index were calculated based on Shuttle Radar Topography Mission data from 2000, and land with $<1 \%$ slope was considered flat. Slope and distance to water were considered continuous variables and were scaled to improve model fitting.

\section{Local ecological knowledge}

The interview component and participatory ranking activities were approved by the Institutional Review Board at Texas A\&M University (College Station, Texas, USA; protocol IRB2016-0279D) and the Botswana Ministry of Tourism and the Environment and the Department of Wildlife and National Parks under permit EWT 8/36/4 XVII (79). All participants provided verbal consent. The results of this research were provided to the regional government offices of Department of Wildlife and National Parks that are responsible for issues related to management and mitigation of human-elephant conflict in Botswana. The results were also shared with various educational and government institutions of Botswana, as outlined in our research permit.

We conducted 25 individual expert interviews across five focal villages during June and July 2017 . We chose four villages near the Okavango River and one inland village to cover a representative range of elephant habitat and areas where elephants caused conflict with people. Local experts were selected for each focal village by deferring to the chief and Village Development Council, a group of local representatives that is established in each village, to adhere to proper protocol and etiquette for working with the villages. Honoraria were not provided to participants, based on the recommendation of the local representatives. We asked the representatives to recommend five individuals from within their village that were considered to be the most knowledgeable on the topic of elephants. We then contacted these community-defined experts to set a date and time to conduct the interview. Only one individual did not consent to the interview, at which time the chief recommended another 
expert. Experts ranged in age from 22 to 75 years old, 23 were male, and they represented four tribal groups, with BaHambukushu the majority. Some interviews were conducted in English, but most were conducted through a translator in Setswana or Simbukushu. The translator was selected based on his language capabilities and extensive knowledge of the landscape and plant species included in the surveys. He was trained on the interview and survey methods, and the same translator was used for all 25 interviews.

As with telemetry and other scientific approaches, social research requires rigorous design and implementation to attain valid and useful results (St. John et al. 2014). We worked to conduct our surveys and ranking activities in a manner that would be consistent and ethical and would minimize bias. Our study location was chosen based on the nearby location of the Ecoexist Trust (http://www.ecoexistproject.org/), a nongovernmental organization that had been working in the region and with local, regional, and national government on the issue of humanelephant coexistence since 2011. The lead researcher for this project had been cooperating and interacting with members of the local government and focal villages for two years prior to this study and had developed trust, respect, and rapport with community members.

The ranking activity was used to provide a standardized and comparable scale of response. Additionally, all further responses that experts discussed were recorded to encourage and validate the sharing of knowledge. The goal of recording information that people provided beyond the ranking activities was to record the knowledge and indicate that we were listening. Lastly, we created an easy method for the experts to opt out of responding to variables or questions they were uncertain of or unfamiliar with, which made it a possible answer on the ranking scale for every single question. During the process, multiple experts did use this option to indicate when they did not know about a certain species, which gave us confidence that we had succeeded in creating an atmosphere in which the experts were comfortable sharing the full breadth of their knowledge.

We used a semistructured interview with three participatory ranking activities (see Appendix 1), and we recorded all responses and additional comments as written notes. The first portion of the interview consisted of general demographic questions and questions about experiences that led to the experts' knowledge of elephants. The second portion of the interview involved participatory ranking activities based on elephant use of plant species, habitats, and landscape features (Table A1 and Fig A1 in Appendix 1). In each of these three categories, experts were asked to rank specific plants, habitat types, or landscape features along a 5-point scale of elephant use, with 1 being "elephants never eat this plant/are never found in this habitat/landscape feature" and 5 being "elephants always eat this plant/are always found in this habitat/landscape feature". Experts were prompted only to rank items that they had knowledge of or were familiar with as to how elephants related to those items. The questions were designed to capture the interviewees' overall expertise about elephants in their local ecosystem, which could then be applied to the vegetation, habitats, and landscape features at different scales. This method is in contrast to participatory mapping or occupancy-related activities, which would take a more specific approach to characterize where the interviewee had directly seen or otherwise experienced elephants.

The plant species survey included 19 species based on our and the translator's knowledge of the area, and the common English and Setswana and/or Simbukushu names for each plant. The habitat survey included 12 habitat types based on the common habitats found in the study area and which were included in the landscape classification map. The habitat survey also included illustrations of the habitat type for clarity. After the initial interviews, experts agreed that the sagebrush habitat was not present in the study area, and so, in addition to consulting existing habitat maps, the sagebrush habitat type was excluded, leaving 11 habitat classes in the survey. The landscape survey included 11 landscape features that we could identify based on topography and existing landscape classifications. The final portion of the interview included questions about elephants' resource use, water sources, movement into the village, crop raiding, and barriers to elephant movement. Experts were invited to share any additional information once the structured questions were concluded.

\section{Telemetry}

We used GPS location data from 15 elephants GPS-collared by The Ecoexist Trust in the western Okavango Panhandle. Individual elephants were collared with the intention of representing independent herds and resource use in varied areas of the landscape. Eight bulls were collared in July 2014 using Africa Wildlife Tracking collars that recorded locations every four hours. An additional six bulls and one cow were collared in 2016 using Africa Wildlife Tracking collars that recorded hourly locations (Appendix 2). Collar deployment was supervised by an experienced veterinarian with permission from the Government of Botswana under research permit EWT 8/36/4 XVII (79) and immobilization permit 2014 WP/RES 15/2/2 XXIII (169). We filtered all tracking data for spurious GPS fixes and error readings.

\section{Local ecological knowledge-based resource selection}

We used the ranks from the participatory ranking activities to collate scores for each vegetation species, habitat type, and landscape feature. We calculated the mean and standard deviation for each variable, and the median and quartiles based on expert responses for each village, and for the entire region including all experts across all villages. We used two spatial interpretations of LEK scores to incorporate into models of resource selection, one based on village-centric expertise, and one based on the combined mean scores. The village-centric approach used the mean scores for each village and applied them to the landscape variables within a set distance zone from the centroid of that village. This approach would capture whether experts' knowledge was most relevant near their own village. If the distance led to overlapping zones between villages, the scores from those villages were averaged for the overlapping portion. We used 25 and $50 \mathrm{~km}$ distances to represent the area for which experts might plausibly have access, experience, and knowledge. The combined mean-score approach incorporated scores from the experts in all focal villages and averaged them across the landscape. This approach would capture whether all experts had relevant knowledge for elephant movement across the region. We again applied this approach at 25 and $50 \mathrm{~km}$ distances, as well as across the entire Panhandle region. For both approaches, scores were then incorporated into a traditional resource selection regression model by multiplying 
the scores by associated spatial values of habitat and landscape features (Boyce et al. 2002). This analysis resulted in selection surfaces at three scales: within $25 \mathrm{~km}$ of focal villages, within 50 $\mathrm{km}$ of focal villages, and the entire Panhandle region. These and all further calculations and analyses were conducted in $\mathrm{R}$ version 3.5.1 (R Core Team 2018).

We used all available GPS collar data from the 15 elephants to assess the predictive capability of the LEK-based resource selection models. We classified the selection surfaces from each approach using k-means clustering in the "classInt" $\mathrm{R}$ package (Bivand et al. 2019) with $k=10$ classes. We then extracted the class values for each of the elephant locations. Elephant locations that occurred outside the targeted areas $(25 \mathrm{~km}, 50 \mathrm{~km}$, or regional) were excluded from the prediction testing. We used Spearman rank correlation to compare the number of elephant locations within each of the 10 selection classes, normalized for area, based on the prediction that greater numbers of elephant presence locations would be found in classes with higher selection values.

\section{Telemetry-based resource selection}

We used a step selection method (Thurfjell et al. 2014) to model elephant use of habitat and landscape features. We calculated the step lengths and turn angles for the measured trajectories of elephant movement using the "amt" package (Signer et al. 2018). Based on the distribution of those step lengths and turn angles, we then generated 10 possible steps for each true step using the "amt" package (Signer et al. 2018). We compared the true steps and the possible steps with a Cox logit regression using the "coxme" package (Therneau 2019), which also allowed us to account for the random effect of individual elephant. We trained the model on the seven elephants collared between 2016 and 2018 over the whole range of their movements, and subset from hourly elephant data to 4-h intervals to reduce temporal dependence. All variables that had environmental data and were correlated with the LEK ranking activity were included in the model (Table 1). To create a final resource selection surface, we predicted selection based on the model coefficients and the values of the environmental variables.

We used the same methods to assess the predictive capability of the telemetry-based resource selection surfaces as the LEK-based surfaces. We used telemetry data from seven individuals to train the model to leave a substantial testing data set. This procedure left data from eight elephants to test the predictive capability for the telemetry-based resource selection surfaces.

\section{Approach complementarity and correlation}

We assessed approach complementarity, concordance, and differences in multiple ways. First, we recognized the different types of information that could be gathered based on the two approaches. The telemetry- and LEK-based approaches generate different types of findings, which may be used separately to answer specific research questions or in combination to provide a more holistic understanding of the system. Next, we assessed concordance between the approaches by comparing how the models ranked habitat and landscape variables at the regional scale. We compared the ranks of the two types of variables based on the LEK scores and step selection function model coefficients using Spearman rank correlation. We expected that if the models agreed with each other, we would find similar ranking patterns for these variables.
Table 1. Conditional logistic regression results for the telemetrybased resource selection function. The model was trained on GPS locations from seven elephants, and a random effect was included to account for elephant individual variation. Variables were chosen to be comparable to those included in the local ecological knowledge ranking activity. Random effect of elephant individual, $\mathrm{SD}=17.34$, $\mathrm{Var}=300.5$.

\begin{tabular}{|c|c|c|c|c|}
\hline Covariate & Coefficient & $\begin{array}{c}\text { Standard } \\
\text { error }\end{array}$ & $Z$ & $P$ \\
\hline Hillslope (scaled) & -0.888 & 0.847 & -1.05 & 0.29 \\
\hline Log distance to water (scaled) & -1.059 & 0.189 & -5.6 & $<0.0001$ \\
\hline Fossilized riverbed & 0.402 & 0.049 & 8.28 & $<0.0001$ \\
\hline Islands & 0.228 & 0.124 & 1.83 & 0.067 \\
\hline Wetland & 1.579 & 1.015 & 1.56 & 0.12 \\
\hline $\begin{array}{l}\text { Low woodland, trees with } \\
\text { shrubs }\end{array}$ & 3.459 & 1.017 & 3.4 & 0.001 \\
\hline $\begin{array}{l}\text { Tall woodland, trees with } \\
\text { shrubs }\end{array}$ & 2.781 & 1.017 & 2.73 & 0.006 \\
\hline Agriculture & 2.455 & 1.016 & 2.42 & 0.016 \\
\hline Dense shrubs with trees & 3.107 & 1.02 & 3.05 & 0.002 \\
\hline Shrubs with trees & 2.972 & 1.015 & 2.93 & 0.003 \\
\hline Shrubs with grass & 2.355 & 1.015 & 2.32 & 0.020 \\
\hline Open grasslands & 2.061 & 1.017 & 2.03 & 0.043 \\
\hline Bare ground with shrubs & 1.976 & 1.017 & 1.94 & 0.052 \\
\hline Flat land & -0.021 & 0.05 & -0.41 & 0.68 \\
\hline Dune crests & -0.019 & 0.033 & -0.58 & 0.56 \\
\hline Dune valleys & 0.342 & 0.028 & 12.16 & $<0.0001$ \\
\hline
\end{tabular}

We then assessed the spatial scale complementarity between telemetry- and LEK-based surfaces by comparing their predictive power. We tested how well the surfaces predicted withheld training elephant GPS locations using Spearman rank correlation. This procedure allowed us to see if the two approaches had similar predictive power across scales or whether they were best suited to different scales and thus complemented each other. Lastly, we plotted the selection surfaces to assess visually the similarities and differences at the regional scale.

\section{RESULTS}

\section{Local ecological knowledge-based resource selection}

The ranking activities generated 445 responses, with on average 23 of 25 interviewees providing a score for each feature. In 49 instances, the expert relayed that they did not know about the feature or elephants' use of it. Experts' knowledge reflected the landscape features related to their village in an expected way; for example, experts from Tsodilo, the village farthest inland, reported that they were unfamiliar with how elephants used floodplains.

Tall and short mopane (Colophospermum mopane), jackalberry (Diospyros mespiliformis), and camelthorn (Vachellia erioloba) were the species ranked highest in terms of elephant foraging (Fig. 2). Zambezi teak (Burkea africana), wild coffee bean (Bauhinia petersiana), and Kalahari apple leaf (Lonchocarpus nelsii) ranked lowest in terms of elephant foraging. There was strongest agreement across experts in all villages that elephants often foraged on tall mopane (mean score \pm SD $=4.4 \pm 0.91$ ), moderately foraged on sickle bush (Senegalia nigrescens; 3.6 $\pm 1.1)$, and did not often forage on Kalahari apple leaf $(2.8 \pm 1.1)$. There was understandably a broader range of answers for general 
vegetation categories such as Combretum spp. $(3.6 \pm 1.5)$ or other Vachellia or Senegalia spp. $(3.4 \pm 1.6)$.

Fig. 2. Scores for the three categories of data collected in the local ecological knowledge participatory ranking activities. Values are calculated based on the combined values from local experts across five focal villages. Boxplots indicate median and quartile values, and mean and standard deviation are reported to the right. Variables are ordered from highest to lowest based on the mean score.

\begin{tabular}{|c|c|c|c|}
\hline Vegetation & 3 & 4 & Mean ( \pm SD) \\
\hline Colophospermum mopane (tall) - & • & & $4.4( \pm 0.91)$ \\
\hline Vachellia erioloba - & - & & $4.2( \pm 1.1)$ \\
\hline Diospyros mespiliformis - & - & & $4.2( \pm 1.2)$ \\
\hline C. mopane (short) - & & & $4.0( \pm 1.3)$ \\
\hline Grewia spp. - & • & & $3.9( \pm 1.0)$ \\
\hline Vachellia tortilis - & - & & $3.9( \pm 1.0)$ \\
\hline Vachellia luederitzii - & & & $3.7( \pm 1.3)$ \\
\hline Combretum spp. - & & & $3.6( \pm 1.5)$ \\
\hline Senegalia nigrescens - & & & $3.6( \pm 1.1)$ \\
\hline Terminalia sericea - & & & $3.4( \pm 1.4)$ \\
\hline Dichrostachys cinerea - & - & & $3.4( \pm 1.2)$ \\
\hline Vachellia, Senegalia spp. - & & & $3.4( \pm 1.6)$ \\
\hline Senegalia mellifera - & - & & $3.2( \pm 1.3)$ \\
\hline Baphia massaiensis - & & & $3.1( \pm 1.4)$ \\
\hline Grasses and reeds - & & & $3.1( \pm 1.2)$ \\
\hline Baikiaea plurijuga - & & & $3.0( \pm 1.3)$ \\
\hline Lonchocarpus nelsii - & & & $2.8( \pm 1.1)$ \\
\hline Bauhinia petersiana - & & & $2.8( \pm 1.4)$ \\
\hline Burkea africana - & & & $2.7( \pm 1.4)$ \\
\hline Habitat type & 1 & 4 & Mean $( \pm S D)$ \\
\hline Dense shrubs with trees & - & & $4.3( \pm 1.1)$ \\
\hline Tall woodland with shrubs - & • & & $4.2( \pm 0.99)$ \\
\hline Shrubs with some trees - & & & $3.9( \pm 0.91)$ \\
\hline Plowed fields - & 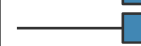 & & $3.7( \pm 1.2)$ \\
\hline Dense shrub thicket - & $\bullet$ & & $3.6( \pm 1.2)$ \\
\hline Shrubs with some grass - & - & - & $3.5( \pm 1.1)$ \\
\hline Low woodland with shrubs & • & - & $3.4( \pm 1.1)$ \\
\hline Unplowed/overgrown fields & & & $3.2( \pm 1.1)$ \\
\hline Grassland, shrubs and trees - & & • & $3.0( \pm 1.2)$ \\
\hline Open grasslands - & & & $2.0( \pm 1.1)$ \\
\hline Bare ground, shrubs - & & & $1.7( \pm 0.75)$ \\
\hline Landscape feature & 1 & 4 & Mean $( \pm S D)$ \\
\hline Permanent river channels - & • & & $4.4( \pm 0.89)$ \\
\hline Islands - & & & $4.3( \pm 0.96)$ \\
\hline Near edges of river - & & & $4.0( \pm 1.1)$ \\
\hline Wet floodplains - & 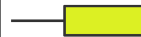 & & $3.4( \pm 1.7)$ \\
\hline Seasonal river channels & & & $2.9( \pm 1.2)$ \\
\hline Dune valleys - & & & $2.9( \pm 1.3)$ \\
\hline Flat land - & & & $2.8( \pm 1.6)$ \\
\hline Fossil riverbeds - & & & $2.7( \pm 1.4)$ \\
\hline Dry floodplains - & & - & $2.6( \pm 1.0)$ \\
\hline Dune sides, hillslopes - & & & $2.2( \pm 1.2)$ \\
\hline Dune crests, hilltops - & • & & $1.3( \pm 0.62)$ \\
\hline
\end{tabular}

There was strong agreement among experts in all villages that elephants were often found in densely shrubbed areas with some trees (mean score $\pm \mathrm{SD}=4.3 \pm 1.1$ ) and tall woodland with shrubs $(4.2 \pm 0.99)$, more moderately in low woodland with shrubs $(3.4$ $\pm 1.1)$, and least often in areas of bare ground with shrubs (1.7 $\pm 0.75)$. There was strong agreement among experts in all villages that elephants preferred to be in permanent river channels (4.4 $\pm 0.89)$ and on islands $(4.2 \pm 0.96)$. There was very strong agreement that elephants were unlikely to be found on top of hills or dune crests $(1.3 \pm 0.62)$.

We calculated the selection surfaces for all approaches and scales (see Fig. 3A for regional scale). Both the combined and villagecentric LEK models positively and significantly predicted the presence of elephants on the landscape at the 25 - and $50-\mathrm{km}$ scales. The village-centric LEK selection model outperformed the combined LEK model at predicting the elephant locations at the 25 - and 50-km scales based on rho values (Table 2).

Fig. 3. Elephant resource selection surfaces predicted across the western Okavango Panhandle region of Botswana. (A) Local ecological knowledge-based resource selection surface. (B) Telemetry-based resource selection surface.

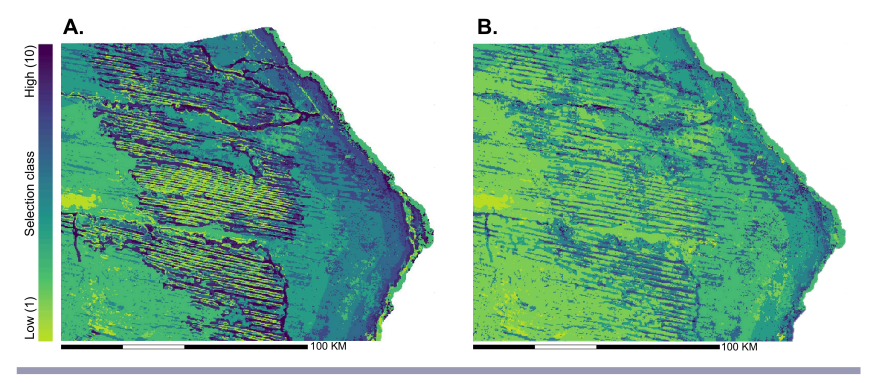

Table 2. Results of Spearman rank correlation for each approach and scale comparing resource selection classifications with testing data from GPS locations from elephant GPS collars, normalized for area.

\begin{tabular}{lcccc}
\hline \hline Approach & Scale & $\mathrm{S}$ & rho & $P$ \\
\hline Local ecological knowledge & & & & \\
village centric & $25 \mathrm{~km}$ & 4 & 0.98 & $<0.0001$ \\
& $50 \mathrm{~km}$ & 10 & 0.94 & $<0.0001$ \\
combined mean & $25 \mathrm{~km}$ & 24 & 0.85 & 0.0035 \\
& $50 \mathrm{~km}$ & 50 & 0.70 & 0.031 \\
& Regional & 32 & 0.81 & 0.082 \\
Telemetry & $25 \mathrm{~km}$ & 14 & 0.92 & 0.0031 \\
& $50 \mathrm{~km}$ & 2 & 0.99 & $<0.0001$ \\
& Regional & 4 & 0.98 & $<0.0001$ \\
\hline
\end{tabular}

\section{Telemetry-based resource selection}

From the step selection analysis, we found that elephants had step lengths on average $1.644 \mathrm{~km}(\mathrm{SD}=1.86 \mathrm{~km})$ per 4-h interval, with on average very low-angle turns (mean $\pm \mathrm{SD}=1.31 \pm 88.1$ degrees leftward).

The telemetry-based elephant resource selection model predicted that elephants strongly selected for closeness to water (Table 1). Elephants also showed positive, significant association with 
wooded habitats, open grasslands, and dune valleys. Elephants showed a negative association with increasing slopes and dune crests, although not significantly.

The telemetry-based model did well at predicting the elephant locations in the test data set at all scales (rho $>0.90$; Table 2). The lowest predictive power was at the $25-\mathrm{km}$ scale.

\section{Approach complementarity and correlation}

Some findings from each method were unique to that method. Descriptive statistics for elephant movements and steps were calculated based on telemetry data. The LEK approach allowed us to rank elephants' preference for different vegetation species, which we were unable to do based on the resolution of telemetry and remotely sensed imagery.

We assessed concordance between the models at the regional scale using rank correlation tests of the habitat and landscape variable scores. In comparing the ranks of the habitat scores of the LEK model and the coefficients calculated from the telemetry step selection model, we found they were positively and significantly correlated (Spearman rank correlation: $\mathrm{S}=22$, rho $=0.74, P=$ 0.046). The bare ground and open grassland habitats ranked lowest for both methods, and woodland and shrubbed habitats ranked highest for both methods. The ranks for landscape features from the two approaches were not correlated $(S=42$, rho $=0.50$, $P=0.22)$; however, selection for dune crests and hillslopes ranked low in both models, whereas the Delta and proximity to water ranked high in both models. Flat land, fossil riverbeds, and dune valleys all clustered in the central range of selection values for both models. Islands were ranked low in the telemetry model, but high in the LEK model.

We then assessed spatial scale complementarity by comparing the predictive power of telemetry- and LEK-based models using Spearman rank correlation. At the broadest spatial scale, the telemetry-based model was highly predictive and was statistically significant, whereas there was no statistically significant predictive model at this scale using the LEK approach (Table 2, Fig. 4). At the $50-\mathrm{km}$ scale, the telemetry model had higher predictive power than the LEK approach, although both methods resulted in positive rho values and statistically significant rank correlations. At the local $25-\mathrm{km}$ scale, the LEK village-centric approach modeled elephant landscape selection with stronger predictive power than the telemetry approach (Table 2, Fig. 4). This result illustrates complementarity at different spatial scales: the telemetry-based model was more predictive at the larger spatial scales, whereas the LEK-based model was more predictive at the local spatial scale.

We plotted the regional extent of elephant landscape use predicted by both LEK (Fig. 3A) and telemetry (Fig. 3B) methods and found that they were visually very similar. We did not measure differences in selection strength because they were based on ranks and therefore would be unlikely to be comparable.

\section{DISCUSSION}

This is the first study to use LEK from community-identified experts to predict African elephant landscape use and to corroborate those results using telemetry. LEK was used to characterize the species of vegetation that elephants use as well as their preferred habitat types and landscape features. At a regional scale, local experts' averaged scores for habitat and landscape features adequately predicted elephant presence. Elephant presence was predicted even more strongly when we accounted for experts' localized knowledge by applying their scores to the area around their home villages. When the area of analysis was locally restricted, the LEK village-centric model outperformed the telemetry-based model in prediction of elephant locations. The telemetry-based model performed well across scales, and both approaches led to similar estimations of the relative strengths of elephant habitat selection. While LEK is valuable in its own right, these complementary findings reinforce the value of LEK data and the potential insights that could be gained by combining different knowledge sources at relevant scales. Moreover, these results highlight the existing natural history knowledge that local experts have about African elephants, a species that they encounter regularly through HWC.

Fig. 4. Plots of the number of elephant locations found within each of the 10 resource selection classes from the local ecological knowledge and telemetry methods, compared at two scales. Area-normalized counts of elephant locations per selection class on the y-axis are scaled from 0 to 1 for ease of plot comparison. The local ecological knowledge plots represent the village-centric approach. Black lines are a visual aid to compare the correlation.

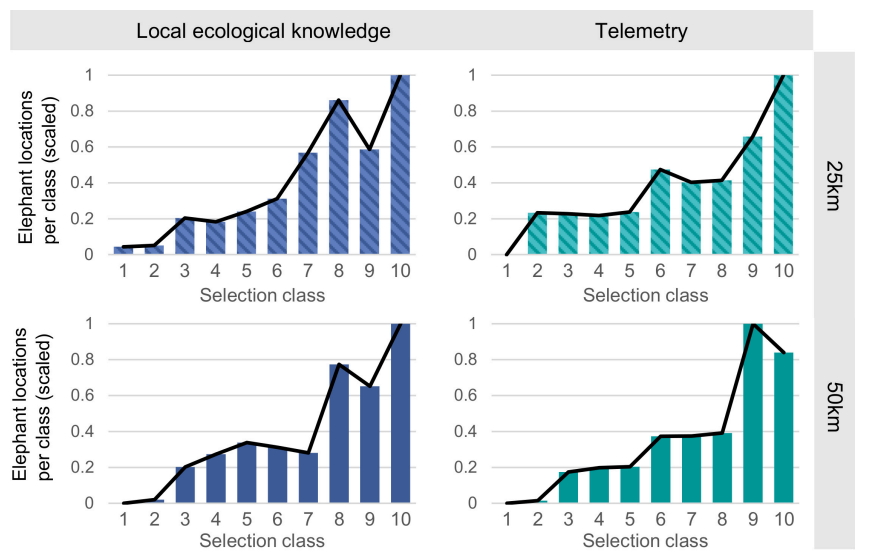

Ranking of elephant preference for different plant species allowed us to capitalize on local expert knowledge without the need for extensive vegetation and foraging sampling. We used LEK scores to estimate elephants' preference for different plant species. Notably, of the 19 species that experts ranked, none had a mean score $<2.7$ out of 5 . This result reflects the generalist diet of elephants, which comprises a broad range of plant matter (Sukumar 2003). Local experts agreed on the species of vegetation that elephants most strongly preferred. The three top-ranked species preferred by elephants are also used by people; mopane trees are harvested for building, camelthorn trees are left uncut for shade, and jackalberry trees are used for woodworking and fruits. The overlapping preference and use by elephants and people could indicate a potential source of conflict where these natural resources are limited. Expert scores for middle- to lowranking species of vegetation had greater variation among them than for high-ranked species. This result could indicate that 
elephants have a strong preference for a few species and browse nonspecifically on a variety of other species, that there is variation in individual elephant foraging preferences, or that experts vary in their familiarity with plant species. Moreover, few experts identified any species of vegetation that elephants avoided or rarely used. This result is in line with elephants' capacity for digesting even fibrous and low-quality materials (Sukumar 2003, Owen-Smith and Chafota 2012), but also alludes to people's understanding that elephants are pervasive and affect all aspects of the environment.

One advantage of this approach is that we were able to characterize elephant preference for a wide variety of species of vegetation very quickly and with detail that would not be possible using the 1- to 4-h telemetry intervals and 250-m remotely sensed vegetation data. Because of these limitations to telemetry data for elephants, alternative methods of collecting foraging data include direct observation (Ruggiero 1992), fecal analysis (Codron et al. 2011), or assessing feeding trails (Owen-Smith and Chafota 2012, Vogel et al. 2019). These methods can provide more detailed insights into seasonal diet variation and selection based on plant characteristics. For our purposes of assessing patterns of vegetation preference, LEK provided an efficient approach to identify the top species selected by elephants in the areas around villages and to highlight their catholic diet of many types of vegetation.

Through participatory ranking activities, we were able to gather LEK and assess elephant preference for habitat and landscape features. There was strong agreement among local experts on the scores for habitat and landscape features, with even lower variation among scores of local experts than those for vegetation. Dune crests and hilltops were the variables with the strongest agreement among experts, and they also had the lowest scores. Thus, experts agreed that elephants are least often found climbing or on top of hills and dunes, which is in accordance with the high energetic costs of elephant movement on slopes (Wall et al. 2006). Wet floodplains had a mid-ranking score but high variation in expert response. In this case, we would recommend iteration and conversation with the experts to assess why there was such wide variation. It could be that there was a difference in interpretation of what constituted a wet floodplain habitat, although we attempted to provide as much clarity and standardization of habitat descriptions as possible.

The ranking of habitat features by experts correlated with the coefficients from the telemetry-based model. This result suggests corroboration in the relative selection of certain habitat types by elephants across different kinds of knowledge. Both approaches placed high importance on proximity to water. In the western Okavango, water is limited to the Okavango River and associated wetlands in the dry season, during which is it very important for elephants (Buchholtz et al. 2019a). In the context of villages, development, and potential interactions with people, experts agreed that elephants are often in dense shrubs and wooded habitats. These habitats are available to elephants near villages, where local experts were likely to encounter them. Wooded habitats are physiologically important to elephants because they need the shade for thermoregulation (Sukumar 2003, Mole et al. 2016) and they also provide protective cover for hiding and food for browsing. Thus, the preference for wooded habitats is ecologically important and supported by both LEK- and telemetry-based approaches.

Whereas water and wooded areas were important in both methods, open grassland had a significant and positive coefficient in the telemetry-based model but was the second-lowest ranking habitat variable in the LEK model. This result sets up the fundamental difference in sampling and scale that is evident from our study. Open grassland was not a common habitat type within $25 \mathrm{~km}$ of the focal villages. Therefore, experts may have had only limited experience seeing elephants or elephant spoor in the context of these habitats. However, open grasslands do exist in the region, and, according to our telemetry-based model, elephants positively and significantly choose them. Additionally, by mapping the difference between the LEK and telemetry predictions across the region, we found that the areas around hillsides and dune valleys showed some of the greatest differences in selection strength. This result may be due in part to the relatively thin and long distribution of these landscape features across the landscape, which may not coordinate well with 1- or 4-h intervals of elephant GPS locations.

LEK provided information at a local scale that was not captured using telemetry. In effect, by surveying local experts, we were able to sample the behavior of all the elephants that were part of the lived experience of the people in the focal villages. We were able to model elephant landscape use around each village and how it differed among villages. The local experts had experience and exposure to more individual elephants near their own villages and over longer periods of time than they did with the elephants for which we had GPS collar data. Future work could focus on exploring the LEK related to longer temporal patterns of elephant behavior to understand how changing environments relate to their behavior. This information would allow scientists to understand responses and drivers of elephant movement better and to design conservation strategies to reduce negative interactions that may result from changing factors. Additionally, by applying experts' scores only to the area around their own village, rather than grouping all experts' knowledge together in a regional model, we were better able to predict elephant landscape use at the local level than we were at an overall averaged regional level. Future work should make sure to consider the area to which LEK is applicable. In our case, understanding where elephants move close to villages provides useful output for local wildlife officers and conservation organizations to target areas that elephants prefer for HWC mitigation and prevention. With limited resources, it is crucial for wildlife officers to prioritize areas to focus their efforts and therefore have the greatest effect on reducing conflict.

The telemetry-based model allowed us to model a resource selection function at different scales with high predictive ability. Because elephant movements were sampled multiple times per day for several years, the data reflected a representative distribution of their presence in different habitat types and landscapes. We found that it had the lowest predictive power at a more local scale restricted around the focal villages. We anticipate the predictive strength could improve if the local scale were limited to areas with high use by collared elephants, rather than by village location. This reflects one limitation of telemetry data, which is that sometimes the scales and areas that we are interested in analyzing do not align with the range and movement of individual collared animals. 
One aim of this work was to support conservationists and policy makers, who are seeking to understand how elephants use the landscape in this region and are managing and mitigating humanelephant conflict. We hope our study highlights how people who regularly interact with wildlife are not mere victims of conflict; rather, they are holders of knowledge, experience, and expertise, and they are well-suited to provide input to analyses of HWC. Our work represents only a single step in engaging local experts in the research process. We encourage future researchers to incorporate local experts throughout the research process to contribute to a more holistic understanding of ecological patterns and processes. This process will lead to insights that we simply cannot gain through biological data alone. It will also serve to acknowledge the value of the knowledge and experiences of people who experience HWC. Lastly, participation in and exposure to the processes behind scientific efforts can positively affect governance, engagement, and support for conservation efforts (McCall and Minang 2005, Treves et al. 2006, Hoare 2015).

Finding ways to invoke LEK in ecological studies is one way of recognizing the expertise of people in local communities who live with elephants and bear the brunt of HWC. In the western Panhandle, as is the case for many remote and rural regions around the world, people do not have access to the institutions that make management decisions, and their experience may be overlooked relative to outside science and technology. We found that an overwhelming majority of the people that we surveyed wanted to share their knowledge and experience. To this end, the results of this research have been provided to the local governing bodies, nongovernmental organizations, regional offices of the Department of Wildlife and National Parks, and various educational and government institutions of Botswana. Our goal is that these findings and the knowledge contributed by individuals in the western Panhandle can be used to inform elephant conservation policies and mitigation strategies for human-elephant conflict in the region.

We aimed to test and highlight the complementarity of the LEKand telemetry-based methods while recognizing the value of both. Critical to this process was that we tested the predictive power of each approach, rather than using results from one approach to test the validity of the other. LEK methods allowed us to understand elephant vegetation preferences and to predict elephant presence at a local scale better than at a regional scale. The lived experiences of local community-defined experts provided efficient and relevant sources of information on African elephant resource selection and landscape use. In contrast, telemetry-based methods allowed us to predict elephant presence better at a larger scale than at a local one. LEK can therefore provide useful information at the relevant scale for certain conservation challenges such as HWC because, although there may be broad patterns in the challenges people and wildlife face when sharing the landscape, solutions to HWC must be local. Incorporating LEK and telemetry as complementary methods at their most relevant scales can then meaningfully contribute to ecology and facing the conservation challenges of HWC for both people and wildlife.
Responses to this article can be read online at: http://www.ecologyandsociety.org/issues/responses. php/11979

\section{Acknowledgments:}

We are thankful to the Government of Botswana Ministry of Environment, Wildlife and Tourism, the Department of Wildlife and National Parks, and the village DiKgosi for giving permission for this research in the Okavango Delta Panhandle. We are particularly grateful to the DiKgosi from Samochima, Xhaoga, Nxamasere, Tsodilo, and Etsha 6 villages. We specifically acknowledge the translation work done by Kelelafetse Phaladi as an employee of the Ecoexist Project. This work would not have been possible without support from the Ecoexist Project, the Howard G. Buffett Foundation, the Amarula Trust, WWF-Namibia, and the National Science Foundation Integrative Graduate Education and Research Traineeship. We thank three anonymous reviewers who provided feedback on the manuscript. The open access publishing fees for this article have been covered by the Texas A\&M University Open Access to Knowledge Fund (OAKFund), supported by the University Libraries.

\section{Data Availability:}

The datalcode that support the findings of this study are available on request from the corresponding author (EKB). The datalcode are not publicly available due to restrictions on sharing of endangered species data and interview information.

\section{LITERATURE CITED}

Anadón, J. D., A. Giménez, and R. Ballestar. 2010. Linking local ecological knowledge and habitat modelling to predict absolute species abundance on large scales. Biodiversity and Conservation 19(5):1443-1454. https://doi.org/10.1007/s10531-009-9774-4

Bender, M. G., G. R. Machado, P. J. de Azevedo Silva, S. R. Floeter, C. Monteiro-Netto, O. J. Luiz, and C. E. L. Ferreira. 2014. Local ecological knowledge and scientific data reveal overexploitation by multigear artisanal fisheries in the southwestern Atlantic. Plos One 9(10):e110332. https://doi. org/10.1371/journal.pone.0110332

Bivand, R., H. Ono, R. Dunlap, M. Stigler, and B. Denney. 2019. Package "classInt". R analysis package. [online] URL: https:// CRAN.R-project.org/package $=$ classInt

Botswana Department of Wildlife and National Parks. 2013. Aerial census of animals in northern Botswana - dry season 2013. Department of Wildlife and National Parks Research and Statistics Division, Gaborone, Botswana.

Boyce, M. S., P. R. Vernier, S. E. Nielsen, and F. K. A. Schmiegelow. 2002. Evaluating resource selection functions. Ecological Modelling 157(2-3):281-300. https://doi.org/10.1016/ $\underline{\mathrm{S} 0304-3800(02) 00200-4}$

Brook, R. K., and S. M. McLachlan. 2008. Trends and prospects for local knowledge in ecological and conservation research and monitoring. Biodiversity and Conservation 17(14):3501-3512. https://doi.org/10.1007/s10531-008-9445-x 
Buchholtz, E. K., L. Fitzgerald, A. Songhurst, G. McCulloch, and A. Stronza. 2019a. Overlapping landscape utilization by elephants and people in the Western Okavango Panhandle: implications for conflict and conservation. Landscape Ecology 34 (6):1411-1423. https://doi.org/10.1007/s10980-019-00856-1

Buchholtz, E. K., L. Redmore, L. A. Fitzgerald, A. Stronza, A. Songhurst, and G. McCulloch. 2019b. Temporal partitioning and overlapping use of a shared natural resource by people and elephants. Frontiers in Ecology and Evolution 7:117. https://doi. org/10.3389/fevo.2019.00117

Codron, J., D. Codron, J. A. Lee-Thorp, M. Sponheimer, K. Kirkman, K. J. Duffy, and J. Sealy. 2011. Landscape-scale feeding patterns of African elephant inferred from carbon isotope analysis of feces. Oecologia 165(1):89-99. https://doi.org/10.1007/ s00442-010-1835-6

Dickman, A. J. 2010. Complexities of conflict: the importance of considering social factors for effectively resolving human-wildlife conflict. Animal Conservation 13(5):458-466. https://doi. org/10.1111/j.1469-1795.2010.00368.X

Gaynor, K. M., C. E. Hojnowski, N. H. Carter, and J. S. Brashares. 2018. The influence of human disturbance on wildlife nocturnality. Science 360(6394):1232-1235. https://doi.org/10.1126/ science.aar7121

Graham, M. D., and T. Ochieng. 2008. Uptake and performance of farm-based measures for reducing crop raiding by elephants Loxodonta africana among smallholder farms in Laikipia District, Kenya. Oryx 42(1):76-82. https://doi.org/10.1017/ $\underline{\text { S0030605308000677 }}$

Gusset, M., M. J. Swarner, L. Mponwane, K. Keletile, and J. W. McNutt. 2009. Human-wildlife conflict in northern Botswana: livestock predation by endangered African wild dog Lycaon pictus and other carnivores. Oryx 43(1):67-72. https://doi.org/10.1017/ $\underline{\mathrm{S} 0030605308990475}$

Hoare, R. 2015. Lessons from 20 years of human-elephant conflict mitigation in Africa. Human Dimensions of Wildlife 20 (4):289-295. https://doi.org/10.1080/10871209.2015.1005855

Kansky, R., M. Kidd, and A. T. Knight. 2014. Meta-analysis of attitudes toward damage-causing mammalian wildlife. Conservation Biology 28(4):924-938. https://doi.org/10.1111/cobi.12275

Kansky, R., M. Kidd, and A. T. Knight. 2016. A wildlife tolerance model and case study for understanding human wildlife conflicts. Biological Conservation 201:137-145. https://doi.org/10.1016/j. biocon.2016.07.002

Kansky, R., and A. T. Knight. 2014. Key factors driving attitudes towards large mammals in conflict with humans. Biological Conservation 179:93-105. https://doi.org/10.1016/j.biocon.2014.09.008

Karanth, K. K., A. M. Gopalaswamy, R. DeFries, and N. Ballal. 2012. Assessing patterns of human-wildlife conflicts and compensation around a central Indian protected area. Plos One 7(12):e50433. https://doi.org/10.1371/journal.pone.0050433

Madden, F. 2004. Creating coexistence between humans and wildlife: global perspectives on local efforts to address humanwildlife conflict. Human Dimensions of Wildlife 9(4):247-257. https://doi.org/10.1080/10871200490505675
McCall, M. K., and P. A. Minang. 2005. Assessing participatory GIS for community-based natural resource management: claiming community forests in Cameroon. Geographical Journal 171(4):340-356. https://doi.org/10.1111/j.1475-4959.2005.00173. $\underline{\mathrm{x}}$

Meijaard, E., K. Mengersen, D. Buchori, A. Nurcahyo, M. Ancrenaz, S. Wich, S. S. U. Atmoko, A. Tjiu, D. Prasetyo, Nardiyono, Y. Hadiprakarsa, L. Christy, J. Wells, G. Albar, and A. J. Marshall. 2011. Why don't we ask? A complementary method for assessing the status of great apes. Plos One 6(3): e18008. https://doi.org/10.1371/journal.pone.0018008

Mole, M. A., S. Rodrigues DÁraujo, R. J. van Aarde, D. Mitchell, and A. Fuller. 2016. Coping with heat: behavioural and physiological responses of savanna elephants in their natural habitat. Conservation Physiology 4(1):cow044. https://doi. org/10.1093/conphys/cow044

Naughton-Treves, L., R. Grossberg, and A. Treves. 2003. Paying for tolerance: rural citizens' attitudes toward wolf depredation and compensation. Conservation Biology 17(6):1500-1511. https://doi.org/10.1111/j.1523-1739.2003.00060.x

Nyhus, P. J. 2016. Human-wildlife conflict and coexistence. Annual Review of Environment and Resources 41(1):143-171. https://doi.org/10.1146/annurev-environ-110615-085634

Oli, M. K., I. R. Taylor, and M. E. Rogers. 1994. Snow leopard Panthera uncia predation of livestock: an assessment of local perceptions in the Annapurna Conservation Area, Nepal. Biological Conservation 68(1):63-68. https://doi.org/10.1016/0006-3207 (94)90547-9

Olsson, P., and C. Folke. 2001. Local ecological knowledge and institutional dynamics for ecosystem management: a study of Lake Racken watershed, Sweden. Ecosystems 4(2):85-104. https:// doi.org/10.1007/s100210000061

Owen-Smith, N., and J. Chafota. 2012. Selective feeding by a megaherbivore, the African elephant (Loxodonta africana). Journal of Mammalogy 93(3):698-705. https://doi.org/10.1644/11MAMM-A-350.1

Parry, L., and C. A. Peres. 2015. Evaluating the use of local ecological knowledge to monitor hunted tropical-forest wildlife over large spatial scales. Ecology and Society 20(3):15. https://doi. org/10.5751/ES-07601-200315

Peace Parks Foundation. 2005. KAZA land cover 2005. ArcGIS hub. World Wildlife Fund, Gland, Switzerland. [online] URL: https://hub.arcgis.com/datasets/b82b036653df4ef8abf184f1c4c656ec? geometry $=-4.235 \% 2 \mathrm{C}-24.265 \% 2 \mathrm{C} 51.883 \% 2 \mathrm{C}-9.599$

Polfus, J. L., K. Heinemeyer, M. Hebblewhite, and Taku River Tlingit First Nation. 2014. Comparing traditional ecological knowledge and western science woodland caribou habitat models. Journal of Wildlife Management 78(1):112-121. https://doi. org/10.1002/jwmg.643

Potten, D. 1976. Etsha: a successful resettlement scheme. Botswana Notes and Records 8:105-119. [online] URL: https://hdl. handle.net/10520/AJA052550590 446

R Core Team. 2018. R: a language and environment for statistical computing. R Foundation for Statistical Computing, Vienna, Austria. 
Ruggiero, R. G. 1992. Seasonal forage utilization by elephants in central Africa. African Journal of Ecology 30(2):137-148. https:// doi.org/10.1111/j.1365-2028.1992.tb00487.x

Signer, J., J. Fieberg, and T. Avgar. 2019. Animal movement tools (amt): $\mathrm{R}$ package for managing tracking data and conducting habitat selection analyses. Ecology and Evolution 9(2). https://doi. org/10.1002/ece 3.4823

St. John, F. A. V., A. M. Keane, J. P. G. Jones, and E. J. MilnerGulland. 2014. Robust study design is as important on the social as it is on the ecological side of applied ecological research. Journal of Applied Ecology 51(6):1479-1485. https://doi.org/10.1111/136$\underline{5-2664.12352}$

Sukumar, R. 2003. The living elephants: evolutionary ecology, behaviour, and conservation. Oxford University Press, Oxford, UK.

Therneau, T. M. 2019. Package "coxme": mixed effects Cox models. R analysis package. [online] URL: https://CRAN.Rproject.org $/$ package $=$ coxme

Thurfjell, H., S. Ciuti, and M. S. Boyce. 2014. Applications of step-selection functions in ecology and conservation. Movement Ecology 2(1):4. https://doi.org/10.1186/2051-3933-2-4

Treves, A., R. B. Wallace, L. Naughton-Treves, and A. Morales. 2006. Co-managing human-wildlife conflicts: a review. Human Dimensions of Wildlife 11(6):383-396. https://doi. org/10.1080/10871200600984265

Tshering, K., and P. Thinley. 2017. Assessing livestock herding practices of agro-pastoralists in western Bhutan: livestock vulnerability to predation and implications for livestock management policy. Pastoralism 7(1):5. https://doi.org/10.1186/ $\underline{\text { s13570-017-0077-1 }}$

Turvey, S. T., C. Fernández-Secades, J. M. Nuñez-Miño, T. Hart, P. Martinez, J. L. Brocca, and R. P. Young. 2014. Is local ecological knowledge a useful conservation tool for small mammals in a Caribbean multicultural landscape? Biological Conservation 169:189-197. https://doi.org/10.1016/j.biocon.2013.11.018

Turvey, S. T., C. T. Trung, V. D. Quyet, H. V. Nhu, D. V. Thoai, V. C. A. Tuan, D. T. Hoa, K. Kacha, T. Sysomphone, S. Wallate, C. T. T. Hai, N. V. Thanh, and N. M. Wilkinson. 2015. Interviewbased sighting histories can inform regional conservation prioritization for highly threatened cryptic species. Journal of Applied Ecology 52(2):422-433. https://doi.org/10.1111/1365-2664.12382

Vanderpost, C., S. Ringrose, and M. Murray-Hudson. 2014. Estimating biodiversity in remote areas, using existing vegetation data: the Ngamiland region. Botswana Notes and Records 45:14. [online] URL: https://journals.ub.bw/index.php/bnr/article/view/400

Vogel, S. M., W. F. de Boer, M. Masake, A. C. Songhurst, G. McCulloch, A. Stronza, M. D. Henley, and T. Coulson. 2019. Do African savanna elephants (Loxodonta africana) eat crops because they crave micronutrients? bioRxiv 673392. https://doi. org/10.1101/673392

Wall, J., I. Douglas-Hamilton, and F. Vollrath. 2006. Elephants avoid costly mountaineering. Current Biology 16(14):R527-R529. https://doi.org/10.1016/j.cub.2006.06.049
Zeller, K. A., K. McGarigal, and A. R. Whiteley. 2012. Estimating landscape resistance to movement: a review. Landscape Ecology 27(6):777-797. https://doi.org/10.1007/s10980-012-9737-0 


\section{Appendix 1, Text 1. LEK survey and participatory ranking activity script}

Write down time start:

First, I'd like to ask you a few questions about yourself.

1. What is your name?

2. How old are you/which year were you born?

3. What is your tribe/ethnicity?

4. What religion do practice/which church do you belong to?

5. What is (or was) your main livelihood?

6. A. How long have you lived in this village? B. Which ward/area do you live in?

7. If you've lived other places, where?

8. What experience do you have that lets you know or learn about elephants?

I'd also like to ask about what elephants seem to like, or what they don't like.

9. Which wild plants/trees do elephants prefer to eat?

10. List of all tree species in veg classification. With help from visual aids: SPECIES SORTING ACTIVITY

A. Rank the ones you are familiar with, by how much elephants like them.

11. Now, what about habitat type?

HABITAT RANKING ACTIVITY

B. Rank the ones you are familiar with, by likelihood of elephant presence.

12. Now I'd like to ask about landscape types.

LANDSCAPE FEATURE RANKING ACTIVITY.

A. Pick the ones you are familiar with and rank them according to elephant presence.

13. Where do elephants get water?

14. What months of the year or seasons are they usually at these places?

15. Do elephants come into the village? If yes, what season/time of day does it happen?

16. Where around your village is there the most trouble related to elephants? For example crop raiding. Based on ward, physical description of the place: north, south, east, west, veld side, river side, etc.

I'd also like to ask about what things are barriers to elephant movements between the dryland and the floodplain.

17. As elephants from the dryland move toward the floodplain, what sorts of things might block their movement or cause them to change their path?

18. As elephants from the floodplain move toward the dryland, what sorts of things might block their movement or cause them to change their path?

19. Do fences block elephants from moving through an area? Veterinary, border fences, electric fences, bush fences, wire fences.

20. What areas do elephants avoid?

21. Do hills affect where elephants move? Do they go over hillslopes or around them?

22. Do you have anything else you would like to share?

Thank you for your participation.

Write down time end: 
Appendix 1, Table 1. Participatory ranking activity choices of plant species, habitats, and landscape features used in the local ecological knowledge interviews.

\begin{tabular}{|c|c|c|}
\hline Plant species & Habitats & Landscape features \\
\hline Grasses and reeds & bare ground with shrubs & hillslope/side of dune \\
\hline Baikiaea plurijuga & dense shrub thicket & top of hill/dune \\
\hline Baphia massaiensis & dense shrubs with some trees & valley between hills/dunes \\
\hline Bauhinia petersiana & low woodland, trees with some shrubs & flat land \\
\hline Burkea africana & open grassland with sage brush* & dry floodplains \\
\hline C. mopane (tall) & open grassland with some shrubs, trees & wet floodplains \\
\hline $\begin{array}{l}\text { Colophospermum mopane } \\
\text { (short) }\end{array}$ & open grasslands & islands \\
\hline Combretum spp. & plowed fields & $\begin{array}{l}\text { old dry river valleys, fossil } \\
\text { riverbed }\end{array}$ \\
\hline Dichrostachys cinerea & unplowed/overgrown fields & permanent river channels \\
\hline Diospyros mespiliformis & shrubs with some grass & $\begin{array}{l}\text { around the edges of the river } \\
\text { channels }\end{array}$ \\
\hline Grewia spp. & shrubs with some trees & seasonal river channels \\
\hline Lonchocarpus nelsii & tall woodland, trees with some shrubs & \\
\hline \multicolumn{3}{|l|}{ Senegalia mellifera } \\
\hline \multicolumn{3}{|l|}{ Terminalia sericea } \\
\hline Vachellia erioloba & & \\
\hline
\end{tabular}

* Removed from analysis due to responses from interviewees that it was not present in the landscape 
Appendix 1, Figure 1. Participatory ranking activity cards used to gather data about elephants' use/preference of plant species, habitats, and landscape features in the local ecological knowledge interviews.
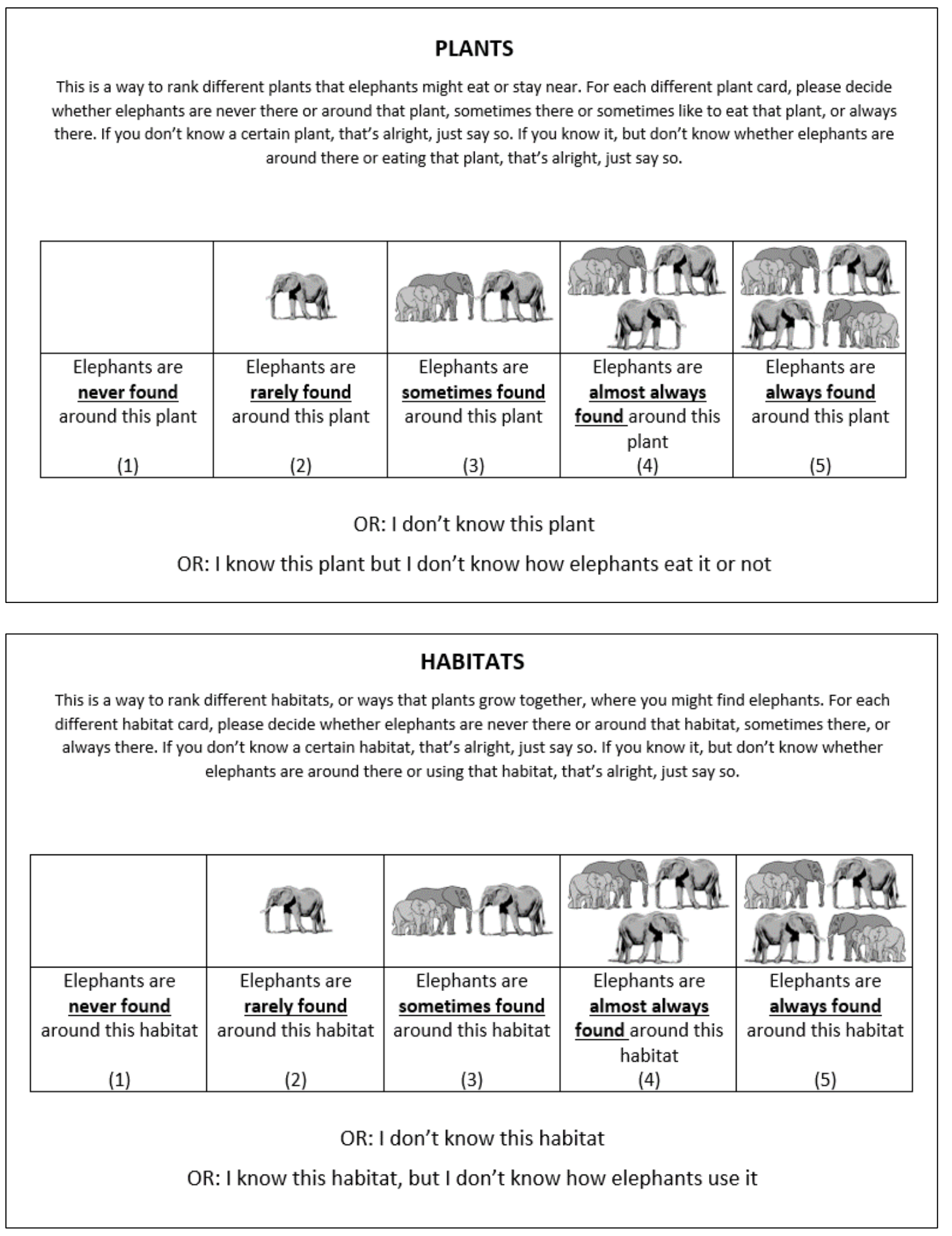


\section{LANDSCAPE FEATURES}

This is a way to rank different landscape features, or parts of the land, where you might find elephants. For each different landscape feature card, please decide whether elephants are never there or around that feature, sometimes there, or always there. If you don't know a certain feature, that's alright, just say so. If you know it, but don't know whether elephants are around there or using that landscape feature, that's alright, just say so.

\begin{tabular}{|c|c|c|c|c|}
\hline $\begin{array}{l}\text { Elephants are } \\
\text { never found } \\
\text { around this } \\
\text { landscape feature } \\
\text { (1) }\end{array}$ & $\begin{array}{l}\text { Elephants are } \\
\text { rarely found } \\
\text { around this } \\
\text { landscape feature } \\
\text { (2) }\end{array}$ & $\begin{array}{c}\text { Elephants are } \\
\text { sometimes found } \\
\text { around this } \\
\text { landscape feature } \\
\text { (3) }\end{array}$ & $\begin{array}{c}\text { Elephants are } \\
\text { almost always } \\
\text { found around this } \\
\text { landscape feature } \\
\text { (4) }\end{array}$ & $\begin{array}{l}\text { Elephants are } \\
\text { always found } \\
\text { around this } \\
\text { landscape feature } \\
\text { (5) }\end{array}$ \\
\hline
\end{tabular}

OR: I don't know this landscape feature

OR: I know this landscape feature, but I don't know how elephants use it 


\section{APPENDIX 2. ELEPHANT GPS COLLAR DATA}

Appendix 2, Table 1. Satellite GPS collaring information for 15 elephants in the Okavango Panhandle Region of Botswana, as carried out by the Ecoexist Project NGO in accordance with the Department of Wildlife and National Parks between 2014 and 2018.

\begin{tabular}{rlrllr}
\hline Elephant ID & Sex & Age set & Collar dates & Collar type & Duration (days) \\
\hline 826 & Male & 36 & $5 / 2016-11 / 2016$ & Vectronic & 192 \\
835 & Male & 26 & $5 / 2016-7 / 2018$ & Vectronic & 778 \\
838 & Male & 40 & $5 / 2016-7 / 2018$ & Vectronic & 781 \\
842 & Male & 26 & $5 / 2016-7 / 2018$ & Vectronic & 779 \\
850 & Female & 20 & $5 / 2016-7 / 2018$ & Vectronic & 781 \\
854 & Male & 50 & $5 / 2016-2 / 2017$ & Vectronic & 287 \\
856 & Male & 50 & $5 / 2016-7 / 2018$ & Vectronic & 780 \\
891 & Male & 36 & $7 / 2014-5 / 2017$ & African Wildlife Tracking & 1050 \\
892 & Male & 36 & $7 / 2014-7 / 2017$ & African Wildlife Tracking & 1090 \\
900 & Male & 50 & $7 / 2014-3 / 2017$ & African Wildlife Tracking & 966 \\
901 & Male & 26 & $11 / 2014-7 / 2017$ & African Wildlife Tracking & 968 \\
902 & Male & 26 & $7 / 2014-3 / 2015$ & African Wildlife Tracking & 254 \\
912 & Male & 26 & $7 / 2014-7 / 2017$ & African Wildlife Tracking & 1090 \\
914 & Male & 50 & $7 / 2014-6 / 2015$ & African Wildlife Tracking & 334 \\
916 & Male & 36 & $7 / 2014-5 / 2016$ & African Wildlife Tracking & 665 \\
\hline
\end{tabular}

